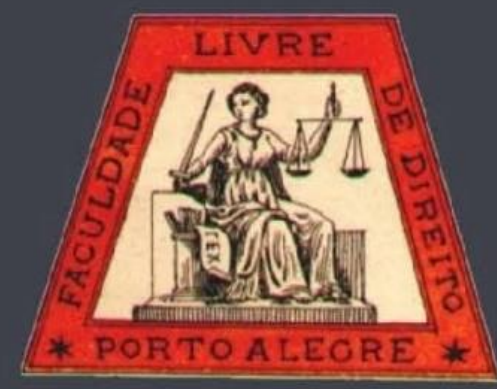

\title{
Regulação e novas tecnologias: verticalização das OTTs de Vídeo
}

Regulation and New Technologies: Vertical Integration of Video OTTS

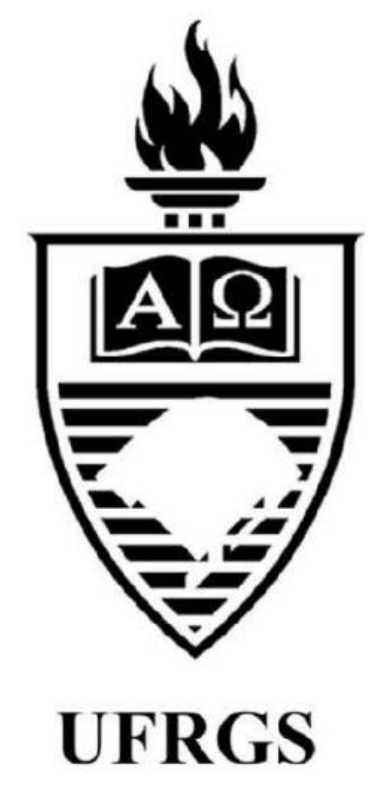

Carlos Emmanuel Joppert Ragazzo Fundação Getúlio Vargas

Isabel Cristina Veloso de Oliveira

Universidade do Estado do Rio de Janeiro 


\title{
Regulação e novas tecnologias: verticalização das OTTs de Vídeo
}

\author{
Regulation and New Technologies: Vertical Integration of Video OTTs
}

\author{
Carlos Emmanuel Joppert Ragazzo* \\ Isabel Cristina Veloso de Oliveira ${ }^{* *}$
}

\section{REFERÊNCIA}

OLIVEIRA, Isabel Cristina Veloso de; RAGAZZO, Carlos Emmanuel Joppert. Regulação e novas tecnologias: verticalização das OTTs de Vídeo. Revista da Faculdade de Direito da UFRGS, Porto Alegre, n. 37, p. 200-218, dez. 2017.

\begin{abstract}
RESUMO
$\mathrm{O}$ artigo procura debater a necessidade de atualização da regulação frente ao desenvolvimento de novas tecnologias. Como tema central: o mercado de TV por assinatura e OTTs, a exemplo da Netflix. A principal pergunta a ser respondida é: Levando em consideração a entrada das OTTs no mercado, a restrição à propriedade cruzada ainda faz sentido? Para responder essa questão, o presente artigo irá explorar, de forma breve, o histórico legislativo e regulatório da restrição da propriedade cruzada em conjunto com uma análise sobre o suposto risco identificado ao mercado na época da imposição da restrição. Ato contínuo, serão analisados dados e funcionalidades do mercado de TV por assinatura em contraste com as inovações, potencialidades, modelo de prestação de serviço e crescimento estrondoso das OTTs de vídeo no Brasil e no mundo, para, ao final, abordar os impactos competitivos e as consequentes assimetrias regulatórias entre os dois modelos (TV por assinatura e OTTs), para sugerir mudanças no modelo regulatório atual.
\end{abstract}

\section{PALAVRAS-CHAVE}

Regulação. TV por assinatura. OTTs. Novas Tecnologias.

\section{ABSTRACT}

The article seeks to discuss the need to update regulation regarding the development of new technologies. As central theme: the pay-TV market and OTTs, like Netflix. The main question is: Given the entry of OTTs into the market, does the cross ownership constraint still make sense? To answer this question, this paper will briefly explore the legislative and regulatory history of the cross-ownership restriction together with an analysis of the alleged risk identified to the market at the time of the imposition of the restriction. In addition, data and functionalities of pay-TV market will be analyzed in contrast to the innovations, potentialities, service delivery model and booming growth of video OTTs in Brazil and worldwide, in order to finally address the competitive impacts and the consequent regulatory asymmetries between the two models (pay-TV and OTTs), to suggest changes in the current regulatory model.

\section{KEYWORDS}

Regulation. Pay-TV. OTTs. New Technologies.

\section{SUMÁRIO}

Introdução. 1 Mudança no paradigma de aprovação da Lei 12.485/2011. 1.1. Histórico legislativo e regulatório sobre a restrição de propriedade cruzada. 1.2. Cenário competitivo após a promulgação da Lei 12.485/2011. 1.2.1. Descrição das

\footnotetext{
* Professor da Escola de Direito da Fundação Getúlio Vargas (FGV). Pós-Doutor em Direito da Concorrência e Política Regulatória (University of California at Berkeley - UCB, 2014). Doutor em Direito da Cidade (Universidade do Estado do Rio de Janeiro - UERJ, 2008). Mestre em Direito Civil (UERJ, 2005). Master of Laws (LL.M) em Direito da Concorrência e Regulação de Mercados (New York University School of Law (NYU, 2002). Graduado em Direito (Pontifícia Universidade Católica do Rio de Janeiro, 1999). Foi Conselheiro do Conselho Administrativo de Defesa Econômica (CADE, 20082012) e seu primeiro Superintendente Geral (2012-2014).

** Pesquisadora do Centro de Justiça e Sociedade da Fundação Getúlio Vargas (FGV-Direito RIO). Doutoranda em Ciência Política (Instituto de Estudos Sociais e Políticos da Universidade do Estado do Rio de Janeiro - IESP/UERJ). Mestre em Ciência Política (IESP/UERJ, 2013). Especialista em Administração Pública (Universidade Federal Fluminense - UFF, 2011). Graduada em Relações Internacionais (UFF, 2016). Graduada em Serviço Social (UFF, 2010).
} 
OTTs. 1.2.2. Impacto competitivo das OTTs no Mercado de distribuição de conteúdo. 2. Estratégia verticalizada (produção + conteúdo) das OTTs: vantagens. 3. Reação dos agentes regulatórios às vantagens das OTTs: assimetria regulatória. Conclusão. Referências.

\section{INTRODUÇÃO}

A Lei 12.485/11, conhecida como Lei da TV Paga, tramitou por cinco anos no Congresso Nacional. À época de sua promulgação e durante grande parte das discussões legislativas, o propósito declarado desse diploma legal consistia na abertura de mercado para novos competidores, ampliação da oferta, estímulo à diminuição do preço final ao assinante, entre outros objetivos. Antes da Lei, o marco regulatório para a comunicação audiovisual no Brasil estava disperso em inúmeros comandos legais.

Com a entrada da lei em vigor, esperava-se alcançar o número de 35 milhões de assinantes de TV por assinatura em cinco anos. ${ }^{1}$ No entanto, essa marca está longe de ser concretizada. Dados divulgados pela Agência Nacional de Telecomunicações (Anatel) ${ }^{2}$ apontam que, em janeiro de 2017 , existiam 18,69 milhões de assinantes de TV por assinatura, pouco mais da metade da previsão es- tabelecida. Além disso, as projeções não são otimistas: apenas no ano de 2016, o setor perdeu 311,3 mil assinantes.

Embora não seja possível estabelecer uma relação causal única para a questão, é possível apontar diversos fatores que contribuem para a recessão do mercado de TV por assinatura, entre os quais a situação econômica do país ${ }^{3}$. No entanto, um fator determinante para a queda registrada é a entrada das Over The Top ${ }^{4}$ - OTTs de vídeo no mercado, serviço online de distribuição de vídeo por assinatura, segmento liderado pela Netflix ${ }^{5}$. Esse novo modelo de prestação de serviço de conteúdo reúne novas possibilidades de relacionamento com o cliente, havendo a produção de conteúdo integrada com a distribuição por meio de plataformas digitais, viabilizando um novo modelo de negócios baseado no uso de Big Data, desenvolvimento de conteúdo próprio e individualização da experiência do usuário.

Particularmente, essa estratégia de verticalização não pode ser utilizada pelas empresas de TV por assinatura. A Lei n. 12.485/11 anteriormente

\footnotetext{
${ }^{1}$ Disponível em: <https://oglobo.globo.com/economia/tv-paga-deve-atrair-35-milhoes-de-assinantes-3549452>. Acesso em: 24 ago. 2017

2 Disponível em: <http://g1.globo.com/economia/noticia/tv-por-assinatura-comeca-2017-com-queda-de-assinantes.ghtml>. Acesso em: 24 ago. 2017.

${ }^{3}$ Desde os primeiros meses de 2015, o Brasil vem passando por uma crise econômica intensificada por um momento de grave instabilidade política. Um dos indicadores econômicos mais significativos, qual seja, a taxa de desemprego, vem se mantendo em patamares alarmantes. O Instituto Brasileiro de Geografia e Estatística (IBGE) apontou que, no trimestre encerrado em maio de 2017, a taxa de desemprego chegou a 13,3\%, o que equivale a 13,8 milhões de desempregados. Além disso, o trabalho com carteira assinada permanece em processo de queda há dois anos, ou seja, embora alguns trabalhadores não estejam sendo computados no número de desempregados, por não estarem procurando emprego, eles vêm caminhando para a informalidade. Outros indicadores, como o PIB e a inflação, também mantém projeções infaustas. O PIB teve uma redução de -3,6\% em 2016 e apresenta perspectiva de crescimento máximo de 0,5\% para 2017, o que pode ser lido como estagnação econômica. Já a inflação chegou a 6,29\% em 2016, algo que substancialmente ocasiona o aumento dos preços e a diminuição do poder de compra do consumidor.

4 "De acordo com o dicionário Oxford, a expressão over the top (OTT) é comumente utilizada para algo que é feito em escalas excessivas ou além de limites razoáveis. Com o tempo, a expressão foi, então, incorporada para denominar serviços de áudio e vídeo pela internet através do streaming." Disponível em: 〈https://en.oxforddictionaries.com/definition/ott〉. Acesso em: 05 dez. 2017.

${ }^{5}$ Disponível em: <https://oglobo.globo.com/economia/numero-de-assinantes-da-netflix-passa-de-100-milhoes-lucro-sobe60-21602347>. Acesso em: 27 ago. 2017.
} 
mencionada previu, no artigo $5^{06}$ e $6^{07}$, a segregação das atividades de programação e distribuição. Ou seja, basicamente existe uma vedação à verticalização da cadeia de valor que compreende prestadoras de telecomunicações, empresas radiodifusoras, produtoras e programadoras (o artigo de lei acima prevê que essa restrição se aplica a produtoras e programadoras com sede no Brasil).

Com a Lei $n^{\circ} 12.485 / 2011$, a Ancine passou a dividir com a Anatel a competência de regular o mercado de comunicação audiovisual de acesso condicionado, por meio de uma lógica baseada em regulação em camadas: conforme definido no art. $4^{\circ}$ do diploma legal acima mencionado, cabe à Ancine $^{8}$ regular atividades relacionadas à produção de conteúdo, empacotamento e programação, enquanto a Anatel $^{9}$ é responsável por regular questões de infraestrutura e distribuição nos serviços de comunicação. A Ancine, por meio da Instrução Normativa ${ }^{\circ} 102 / 12^{10}$, interpretou que pessoas ju-

\begin{abstract}
6 “Art. 5 $\mathrm{O}$ controle ou a titularidade de participação superior a $50 \%$ (cinquenta por cento) do capital total e votante de empresas prestadoras de serviços de telecomunicações de interesse coletivo não poderá ser detido, direta, indiretamente ou por meio de empresa sob controle comum, por concessionárias e permissionárias de radiodifusão sonora e de sons e imagens e por produtoras e programadoras com sede no Brasil, ficando vedado a estas explorar diretamente aqueles serviços. $\S 1$ o $\mathrm{O}$ controle ou a titularidade de participação superior a $30 \%$ (trinta por cento) do capital total e votante de concessionárias e permissionárias de radiodifusão sonora e de sons e imagens e de produtoras e programadoras com sede no Brasil não poderá ser detido, direta, indiretamente ou por meio de empresa sob controle comum, por prestadoras de serviços de telecomunicações de interesse coletivo, ficando vedado a estas explorar diretamente aqueles serviços. "

7 "Art. $6^{\circ}$ - As prestadoras de serviços de telecomunicações de interesse coletivo, bem como suas controladas, controladoras ou coligadas, não poderão, com a finalidade de produzir conteúdo audiovisual para sua veiculação no serviço de acesso condicionado ou no serviço de radiodifusão sonora e de sons e imagens: I - adquirir ou financiar a aquisição de direitos de exploração de imagens de eventos de interesse nacional; e II - contratar talentos artísticos nacionais de qualquer natureza, inclusive direitos sobre obras de autores nacionais"
\end{abstract}

${ }^{8}$ Lei 12.485/2011: Art. 9. As atividades de produção, programação e empacotamento são livres para empresas constituídas sob as leis brasileiras e com sede e administração no País. Parágrafo único. As atividades de programação e de rídicas que exerçam atividades de produção, programação e empacotamento, ainda que tenham sede no exterior, estarão sujeitas à legislação brasileira. Fica claro, portanto, que o órgão regulador do governo passado tentava aprofundar o modelo de proibição à verticalização. A partir dos próximos itens, este artigo irá avaliar se esse movimento faz sentido diante das novas tecnologias.

\section{MUDANÇA NO PARADIGMA DE APRO- VAÇÃO DA LEI 12.485/2011}

\subsection{Histórico legislativo e regulatório sobre a restrição de propriedade cruzada}

Antes de se tornar a Lei $12.485 / 11$, a chamada "Lei da TV Paga" tramitou na Câmara como

empacotamento serão objeto de regulação e fiscalização pela Agência Nacional do Cinema - Ancine no âmbito das competências atribuídas a ela pela Medida Provisória no 2.2281 , de 6 de setembro de 2001.

${ }^{9}$ Art. 29. A atividade de distribuição por meio do serviço de acesso condicionado é livre para empresas constituídas sob as leis brasileiras, com sede e administração no País, sendo regida pelas disposições previstas nesta Lei, na Lei no 9.472, de 16 de julho de 1997, e na regulamentação editada pela Agência Nacional de Telecomunicações - ANATEL. Parágrafo único. A ANATEL regulará e fiscalizará a atividade de distribuição.

10 “Art. $2^{\circ}$ As atividades de produção, programação e empacotamento no Brasil são livres para empresas constituídas sob as leis brasileiras e com sede e administração no país. § $1^{\circ} \mathrm{O}$ exercício da atividade de programação do exterior para o Brasil somente será permitido às programadoras estrangeiras que se sujeitarem às leis e foro brasileiro, quanto aos atos ou operações praticados no exterior que produzam efeitos no Brasil, incluindo as obrigações previstas na Lei $\mathrm{n}^{\circ}$ $12.485 / 2011$, nos mesmos termos em que se aplicam às empresas com sede no Brasil. $\S 4^{\circ}$ A programadora estrangeira que exerça atividade de programação do exterior para o Brasil está obrigada a manter, permanentemente, representante único no país, com poderes para resolver quaisquer questões e receber intimação e notificação administrativa e citação judicial em nome da empresa estrangeira". Disponível em: $<$ https://www.ancine.gov.br/pt-br/legislacao/instrucoes-normativas-consolidadas/instru-o-normativa-n-102-de-19-dejunho-de-2012>. 
PL 29/2007 ${ }^{11}$ e no Senado como PLS 116/2010 ${ }^{12}$. Como parâmetro para comparação, a tecnologia na época da tramitação pode ser retratada da seguinte forma: houve o lançamento do Windows Vista, início da comercialização do iPhone, o Orkut era a rede social mais utilizada, o Wii liderava a venda de consoles e o Brasil assistia a chegada da TV digital, embora ainda fosse levar quase uma década até que essa tecnologia alcançasse a maior parte dos domicílios no país. O próprio mercado de TV por assinatura era outro, os pacotes de TV e internet (e telefone, em alguns casos) começavam a ganhar força com o desenvolvimento da internet de alta velocidade, o que fez com que o setor alcançasse 5,3 milhões de assinantes no final de 2007, com alta de $13 \%$ sobre $2006^{13}$.

Foi nesse contexto que o PL 29/2007 começou a tramitar na Câmara, tendo sido apresentado pelo então deputado Paulo Bornhausen (PFL/SC) em $05 / 02 / 2007$. No momento de sua apresentação, o PL pretendia alterar aspectos polêmicos da Lei do Cabo, como a restrição à presença de capital estrangeiro ${ }^{14}$. No entanto, ao longo dos anos de tramitação, alguns objetivos de liberalização foram se perdendo, surgindo restrições à propriedade cruzada entre os setores de telecomunicações e de radiodifusão (art. $5^{\circ}$, caput e $\S 1^{\circ}$ ), e a segmentação da cadeia de valor do audiovisual (art. $6^{\circ}$, I e II), separando as atividades de produção de conteúdo e de transmissão do produto ao consumidor final.

\footnotetext{
11 Disponível em: <http://www.camara.gov.br/proposicoesWeb/fichadetramitacao?idProposicao=339998>.

12 Disponível em: <https://www25.senado.leg.br/web/atividade/materias/-/materia/97352>. Acesso em: 05 set. 2017.

13 Disponível em: <http://www1.folha.uol.com.br/fsp/dinheiro/fi1603200817.htm>. Acesso em: 05 set. 2017.

${ }^{14}$ Como pode ser identificado na obra de Possebon (2009), desde os primeiros esforços para regulamentar a TV a cabo, sempre existiu uma diferenciação entre as empresas brasileiras e estrangeiras. Nessa época, o ramo da comunicação social no Brasil era baseado em empresas de rádio, TV e imprensa escrita, ambas sujeitas a regime de forte censura. Foi exigido, portanto, que apenas brasileiros pudessem ser acionistas de empresa dessa natureza, como uma das medidas para evitar que as operações de TV a cabo se tornassem forma de disseminação de "informações subversivas" Cf
}

A medida de restrição à propriedade cruzada começou a ser debatida a partir do escopo do PL $70 / 2007^{15}$, que logo após sua apresentação foi apensado ao PL 29/2007. O autor do Projeto, Dep. Nelson Marquezelli (PTB-SP), tinha como preocupações centrais: "1) a defesa da soberania e da identidade nacionais, incluindo o desenvolvimento da cultura e a proteção do patrimônio cultural brasileiros; e 2) a manutenção do pluralismo e da liberdade de circulação de ideias, exigindo a prevenção de condutas anticoncorrenciais no setor". Durante a tramitação do PL 29/2007, o motivo para a restrição à propriedade cruzada, que aparece de forma predominante nos pareceres publicados pelas Comissões durante a tramitação do Projeto de Lei, é a intenção de promover a competição, a partir de uma ampliação do número de players, limitando a capacidade de alguns agentes dominarem o setor, preocupação da qual compartilhei à época. Basicamente, para nomear os agentes econômicos que traziam preocupação à época, os legisladores entendiam que as empresas de telecomunicações teriam faturamentos muito maiores do que empresas produtoras, podendo trazer suposta distorção ao mercado, cuja solução, ao ver da legislatura à época, seria resolvida por meio das restrições na participação cruzada entre os setores de audiovisual e telecomunicações ${ }^{16}$. Durante a tramitação, diversas emendas foram apresentadas com o intuito de flexibilizar ou adensar ainda mais

POSSENON, Samuel. TV por assinatura: 20 anos de evolução. São Paulo: Save Produções, 2009.

15 Disponível em: <http://www.camara.gov.br/proposicoesWeb/fichadetramitacao?idProposicao=340222>.

Acesso em: 24 set. 2017.

16 "Participação cruzada de capital entre empresas de telecomunicações e do audiovisual. Um dos principais argumentos que embasaram a demanda por uma nova disciplina na comunicação audiovisual eletrônica por assinatura consistiu na verificação da necessidade de ampliar o número de atores nesse segmento, com vistas a fomentar a competitividade e, por consequência, elevar a penetração e a qualidade dos serviços. Ao longo dos debates acerca do assunto, contudo, consolidou-se, de forma quase unânime, a compreensão de que a abertura indiscriminada do mercado poderia ter efeitos nefastos, dada, principalmente, a potencialidade de ingresso de competidores com excessivo poder de mercado. Nessa linha, 
essa norma. No entanto, nenhuma obteve sucesso e a regra de proibição de propriedade cruzada permaneceu.

\subsection{Cenário competitivo após a promulgação da Lei $12.485 / 2011$}

Atualmente, com a Revolução 4.0 e as dificuldades quanto à modularidade do mercado de serviços em um cenário cada vez mais fragmentado, a situação é bem diversa daquela que fomentou a discussão da Lei $12.485 / 11$ e que motivou a proibição à verticalização. A tecnologia digital e a internet tiveram um papel muito importante na remodelagem da indústria audiovisual, redesenhando a dinâmica competitiva dos agentes econômicos. Given et al. (2012) ${ }^{17}$ afirmam que essa nova tecnologia criou uma janela de oportunidades para serviços de vídeos inovadores e abriu margem para que empresas desempenhassem um papel mais ativo no que concerne à produção, financiamento, agregação e distribuição de programação, ultrapassando seus papéis tradicionais de transmissão de canais e alcançando um posicionamento estratégico no mercado de distribuição de conteúdo. Para entender propriamente o papel competitivo das OTTs, em especial da Netflix, é importante descrever brevemente suas características, antes de demonstrar o respectivo efeito prático na concorrência.

\subsubsection{Descrição das OTTs}

para assegurar um aumento prudente dos atores e a manutenção de condições equilibradas de concorrência na futura formatação do mercado, decidiu-se pela imposição de restrições na participação cruzada entre os setores de telecomunicações e de audiovisual" (Parecer da Comissão de Defesa do Consumidor às Emendas ao Substitutivo do Relator Deputado Vital do Rêgo Filho) (...) "Considerando a discrepância entre a magnitude dos faturamentos dos setores de telecomunicações e de produção de audiovisual, optamos por acatar a referida emenda. A medida permitirá que sejam evitadas potenciais distorções induzidas por aplicações massivas de capitais transnacionais na produção artística e cultural nacio-
OTT (Over The Top) trata-se do fornecimento de aplicações de telefonia, streaming de vídeo, mensagens instantâneas e chats por meio da internet, geralmente baseados em plataformas multiuso, a exemplo de computadores, SmartTVs, videogames e celulares. Como define a Organização para a Cooperação e Desenvolvimento Económico (OECD), o termo OTT se refere a vídeos, músicas e outros serviços prestados por meio da Internet, em detrimento das redes gerenciadas próprias dos provedores $(\mathrm{OECD}, 2013)^{18}$. Os serviços transmitidos pelas OTTs não requerem serviços de transportadora, venda, provisionamento ou atendimento (Wedge \& Lancaster, 2007) ${ }^{19}$. Como os gastos com infraestrutura são baixos, somado a outros fatores, as OTTs podem oferecer preços mais atrativos ao consumidor, gerando grande impacto em diversas vertentes do setor de comunicações (telefonia fixa e móvel, TV por assinatura e Serviço de Valor Adicionado - SVA).

Dentre as aplicações $O T T$, existem serviços como: 1- Subscription Video on Demand (SVOD), serviço online com a cobrança de assinatura - a exemplo da Netflix e a AmazonPrime; 2- Transactional Video on Demand (TVOD), serviços que cobram o usuário com base na locação ou acesso de curto prazo - a exemplo da Apple iTunes e Google Play e Advertising Video on Demand (AVOD), serviço oferecido gratuitamente e com suporte de anúncios, a exemplo do YouTube e Crackle. Embora todos esses sejam pertinentes

nal". Cf. Parecer da Comissão de Ciência e Tecnologia, Comunicação e Informática ao Substitutivo ao Projeto de Lei ${ }^{\circ}$ 29, de 2007.

${ }^{17}$ GIVEN, J., CURTIS, R.; MCCUTCHEON, M. Online video in Australia. International Journal of Digital Television, v. 03, n. 02, p. 141-162, 2012.

18 OECD. OECD Communications Outlook 2013. Paris: OECD Publishing, 2013. Disponível em: <http://dx.doi.org/10.1787/comms_outlook-2013-en>.

Acesso em: $31 \mathrm{dez} .2017$.

${ }^{19}$ WEDGE, G.; Lancaster, B. Over-the-Top Services. Pipeline, v. 04, n. 07, 2007. Disponível em: <http://www.pipelinepub.com/1207/pdf/Article_3.pdf $>$. Acesso em: $31 \mathrm{dez}$. 2017. 
para o que se pretende para o presente artigo, vale a pena aprofundar a descrição dos $V o D$ s.

O Conselho Superior do Cinema aponta os elementos que caracterizam o vídeo sob demanda: (a) um serviço de comunicação de conteúdos audiovisuais; (b) organizado em catálogo; (c) ofertado ao público em geral ou a assinantes; (d) de maneira não linear; (e) por meio de redes de comunicação eletrônica, dedicadas ou não; (f) com finalidade res/compradores tradicionais, revertendo as preocomercial, sendo remunerado diretamente pelo cupações competitivas inicialmente identificadas usuário (por meio de compras avulsas ou assina- para justificar a implementação de medidas de restura) e/ou por venda de espaço publicitário, e (g) trição de propriedade cruzada:

Figura 1 - Cadeira de valor audiovisual

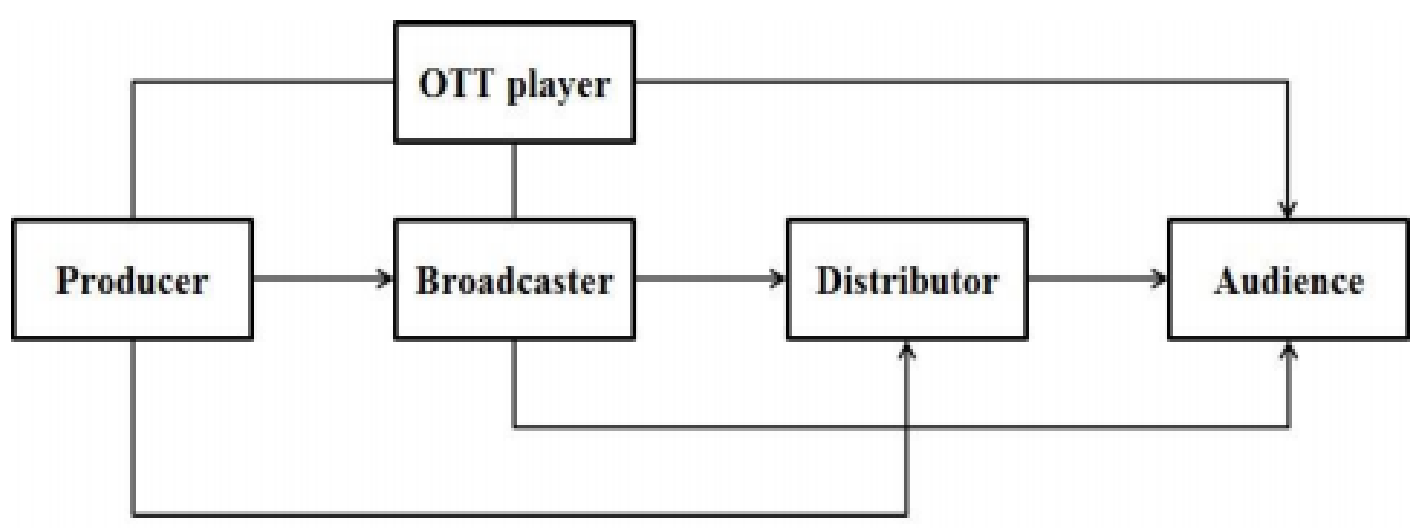

Dentre os OTTs, um setor que vem cres- e vídeos em Ultra HD. O impacto vem sendo sencendo aceleradamente é o de vídeo. A Netflix, que tido pelas empresas de TV por assinatura por meio anteriormente funcionava como uma empresa de do cancelamento total do serviço ou do downgrade aluguel de DVDs, iniciou o streaming service em dos planos ${ }^{22}$. Isso se dá, basicamente, porque, para 2007, inaugurando a categoria OTT SVOD. O ser- o consumidor, não há diferença se o conteúdo é viço é ofertado a preços mais baixos que uma TV acessado por meio de uma TV por assinatura (cabo por assinatura, com valores de $\mathrm{R} \$ 19,90$ a $\mathrm{R} \$ 37,90$ ou DTH) ou por meio da internet, especialmente (2017). Dentre outras vantagens, o pacote mais num contexto em que o crescimento da cobertura caro inclui quatro telas de visualização simultânea de banda larga cresce agressivamente.

20 Disponível em: <https://www.ancine.gov.br/sites/default/files/CSC $\% 20-\% 20$ Consolida\%C3\%A7\% $3 \%$ A3o\%20Desa-

cipais aplicações de mensagens sociais normalmente utilizadas em smartphones em todo o mundo e concluiu que as empresas de telefonia perderam cerca de $\$ 13,9$ bilhões com fios\%20VoD\%2017\%2012\%2015_1.pdf>. Acesso em 24 SMS. Essa perda certamente se agravou, dado que, em feveago. 2017.

${ }^{21}$ Op. cit. reiro de 2016, só o Whatsapp alcançou a marca 1 bilhão de usuários (segundo o controle da própria empresa). O avanço

${ }^{22}$ Os serviços de OTT, de modo geral, trouxeram desafios para diversos segmentos do setor de telecomunicações. Um levantamento não tão recente, realizado em 2011 pela empresa britânica Ovum, avaliou as estatísticas de uso das prin- da tecnologia trouxe alternativas dinâmicas e eficientes, conquistando uma parcela significativa de consumidores e transformando esse nicho de mercado, forçando as empresas a refazerem seus planos de negócios. 
O surgimento da Internet como uma plataforma viável de distribuição de vídeo produz dois principais efeitos na economia da Televisão tradicional: em primeiro lugar, reduz as restrições de capacidade no estágio de distribuição e, relacionado a isso, reduz o custo de entrega dos conteúdos e serviços de televisão (Waterman, 2001) ${ }^{23}$. Além disso, cria a possibilidade tecnológica de uma alternativa à visão linear, ou seja, cria a capacidade de assistir programas de televisão no tempo de escolha (D’Arma, 2011) ${ }^{24}$.

\subsubsection{Impacto competitivo das OTTs no mercado} de distribuição de conteúdo

Essa nova estrutura atende a novos anseios de demanda por entretenimento. O serviço proporciona a facilidade de acessar conteúdo a qualquer hora e local, desde que haja dispositivos com acesso à internet (computadores, Smart tv, smartphones, videogames, tablets, entre outros). Tratase de uma experiência sob demanda que possivelmente terá um crescimento ainda maior com a ampliação do acesso da população a esses dispositivos. Na verdade, as OTTs se inseriram como um novo player que tornou a cadeia mais complexa, caracterizada pelo surgimento de (potenciais) mo- delos de negócios disruptivos à produção e à distribuição de conteúdo, trazendo também o fenômeno de desintermediação, a exemplo de outros mercados que experimentam movimento semelhante ${ }^{25}$. Na prestação dos serviços de distribuição de conteúdo, as OTTs efetivamente descartam os operadores de cabo/satélite, e usam a tecnologia para criar um relacionamento direto com o cliente.

Mas o que isso significa para o mercado de produção e distribuição de conteúdo? Apenas para ficar com o exemplo mais relevante, é importante notar que a Netflix vem se mantendo em crescimento acelerado e constante. Dados de 2017, levantados pelo Leichtman Research Group, apontam que nos Estados Unidos o número de assinantes da Netflix superou o número de assinantes da TV por assinatura ${ }^{26}$. Assim como no Brasil, a TV a cabo tem perdido usuários no país, chegando a um déficit de 4 milhões de usuários em 5 anos.

O gráfico 01 mostra como se deu a evolução do número de assinaturas de OTTs nos EUA e apresenta uma projeção, a partir do ano de 2017, que indica que as OTTs devem superar a TV por assinatura em 2018, embora os dados apresentados anteriormente, do Leichtman Research Group, mostrem que o resultado foi ainda melhor do que o esperado (já que as OTTS já teriam superado este ano a TV por Assinatura).

\footnotetext{
${ }^{23}$ WATERMAN, David. The Economics of Internet Television: New Niches vs Mass Audiences. Info: the Journal of Policy, Regulation and Strategy for Communications, Information and the Media, v. 03, n. 03, p. 215-228, 2001.

que, com o avanço da tecnologia, podem ser facilmente adquiridas pelo consumidor sem o intermédio de agências de viagens.

26 "The survey also found that $54 \%$ of adults report that they ${ }^{24}$ D'ARMA, Alessandro. Content aggregation in the age of have Netflix in their household, while $53 \%$ have a DVR. This online video: an analysis of the impact of internet distribution on the television business. Journal of Media Business Studies, v. 08, n. 03, p. 1-17, set. 2011. is the first time that households with Netflix (including those sharing passwords) have surpassed the level of those with a DVR. In 2011, 44\% of TV households had a DVR and $28 \%$ ${ }^{25}$ A exemplo do mercado financeiro que, cada vez mais, had Netflix." Disponível em: <http://www.leichtmanreseexige menos intermediações para a execução de transações arch.com/press/030617release.html>. Acesso em: 26 ago. ou a aquisição de passagens aéreas ou a reservas de hotéis 2017.
} 


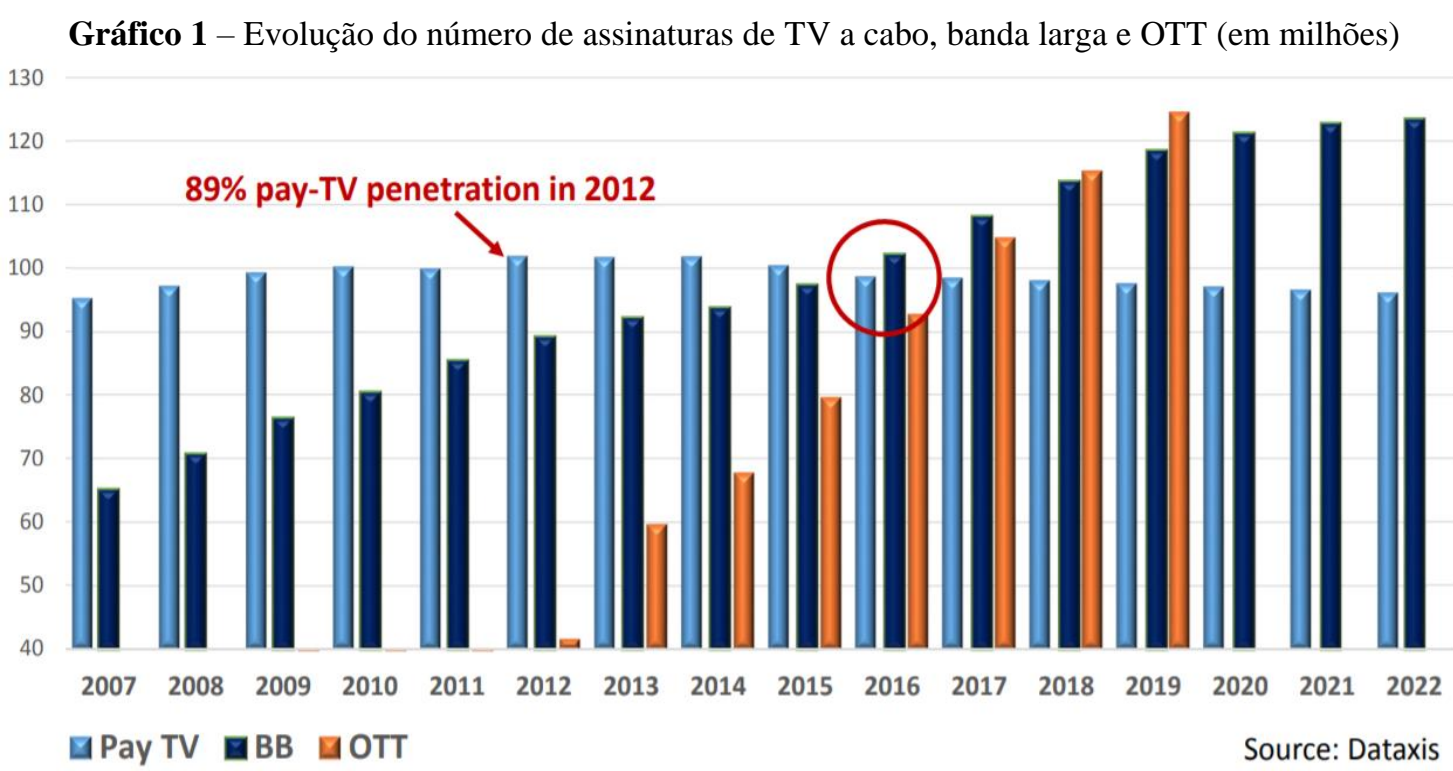

No Brasil, é possível prever um resultado se- (em termos de percentagem de consumidores que melhante. Diversos dados apontam o crescimento são assinantes de OTT), seguido pelos Estados acelerado do setor que, em 2016, atingiu a marca Unidos, onde 55\% são assinantes de serviços OTT. de seis milhões de assinantes no Brasil e um fatu- A pesquisa, encomendada pela Paywizard e realiramento de $\mathrm{R} \$ 1,290$ bi, 30\% superior ao do SBT, zada pela Research Now, avaliou mais de 6.200 por exemplo. Além disso, uma pesquisa divulgada consumidores em todo o mundo, incluindo 1.052 em dezembro de 2016 pela Paywizard mostra que brasileiro ${ }^{27}$. Em movimento contrário, depois de $30 \%$ dos consumidores brasileiros planejavam as- um pico em 2014, o setor de TV por Assinatura sinar pela primeira vez um serviço de OTT, sendo vem registando queda. No ano de 2016, a TV por que $70 \%$ planejam manter a prestação do serviço Assinatura no Brasil teve uma queda de 1,63\% em por mais de 6 meses. Em 12 meses a procura pelo relação ao ano anterior, o que equivale 311.362 asserviço subiu de $29 \%$ para $53 \%$. O setor de OTT sinantes:

brasileiro é agora o segundo maior em uma pes-

quisa de seis mercados internacionais de televisão

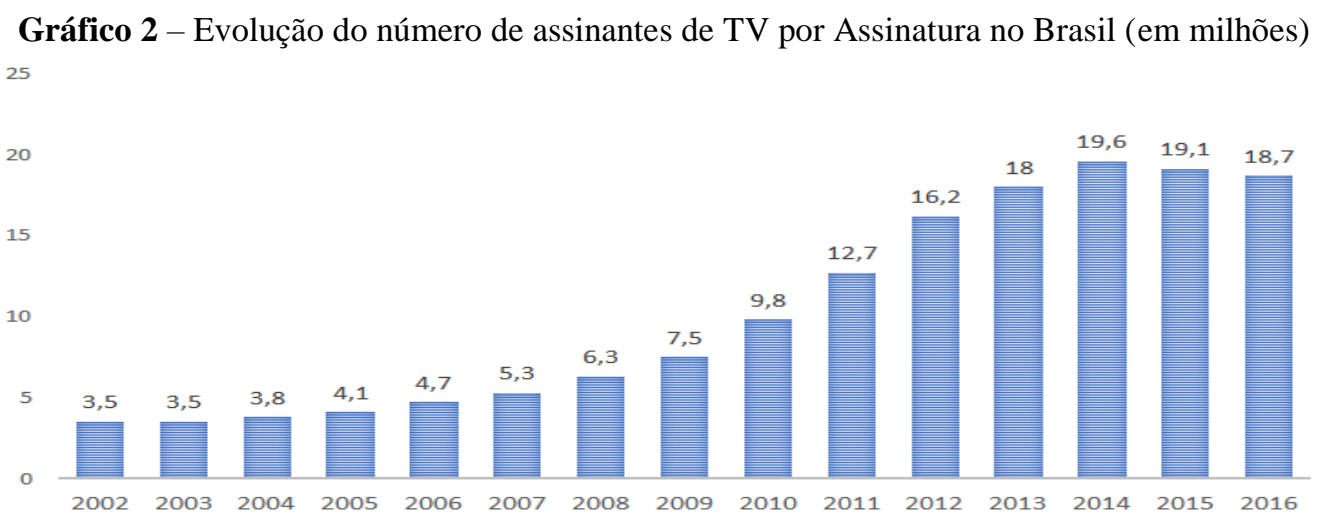

Fonte: PTS até 2008 - Anatel/ABTA a partir de 2009 - mês base: abril/2017.

\footnotetext{
${ }^{27}$ Disponível em: <https://www.paywizard.com/blog/brazi- christmas-paywizard-survey-shows/>. Acesso em: 26 ago. lians-hungry-top-pay-tv-half-consumers-plan-subscribe2017.
} 
Saindo dos números agregados, de forma a feita apenas a Oi e a Cabo, que apresentaram índivisualizar as perdas por operadora, é possível veri- ces positivos (a Oi cresceu 11,61\% e a Cabo cresficar que todas as empresas de TV por Assinatura ceu 1,44\% no período abaixo indicado). vêm registrando perdas de assinantes, exceção

Gráfico 3 - Evolução do número de assinantes de TV por Assinatura por operadora/grupo (em milhões)

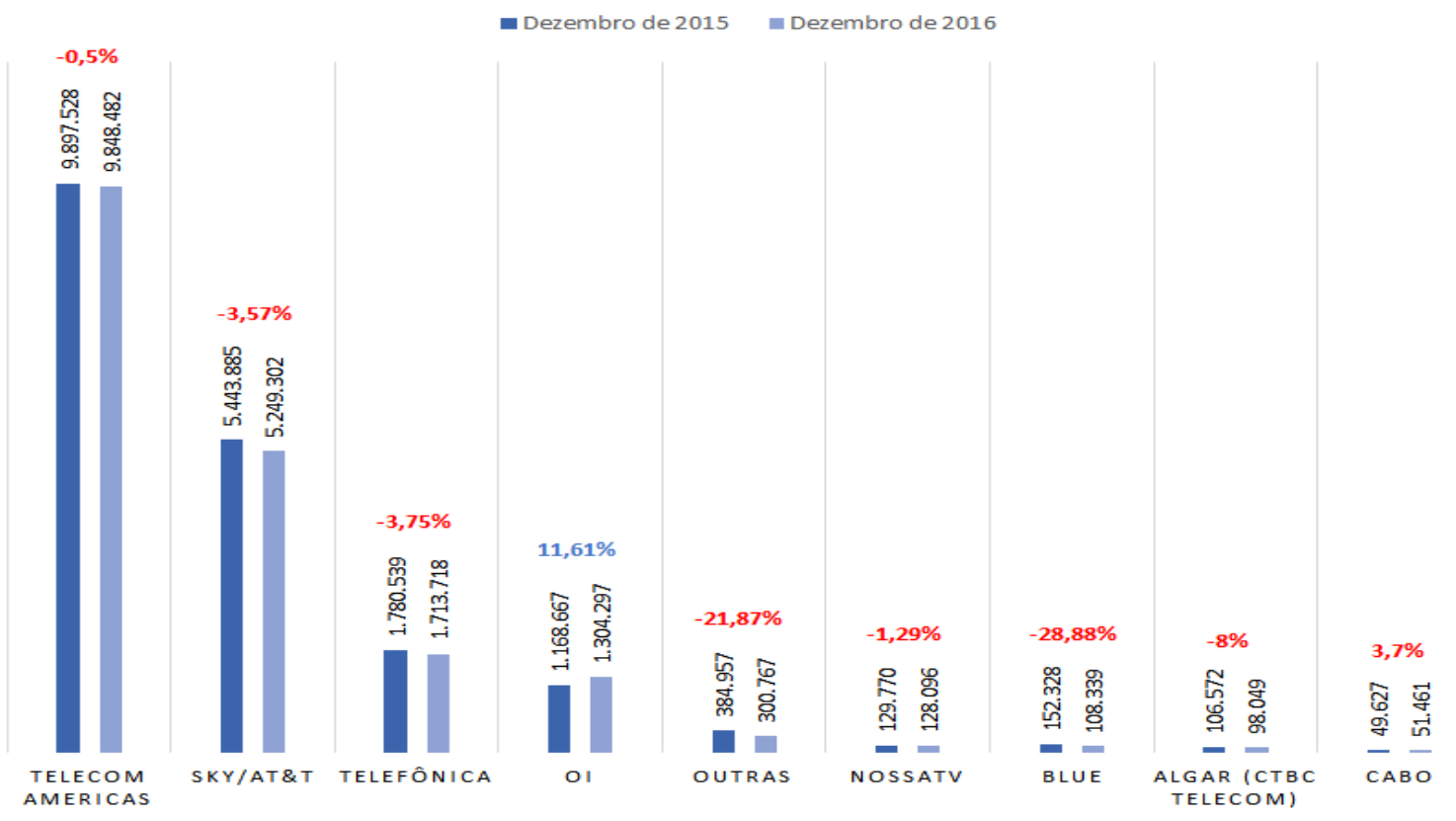

Fonte: Anatel 2017.

Para demonstrar que os dados acima não es- evolução com perspectivas bastante otimistas para tão exclusivamente relacionados ao momento de um futuro próximo. A presença dessa estrutura tem recessão da economia brasileira, além da tendência se mostrado o principal fator para as OTTs de víde mercado verificada nos Estados Unidos acima deo (além de os próprios aparelhos de TV já virem mencionada, é importante revelar que o cresci- adaptados ao modelo smart): mento de banda larga vem mantendo o padrão de

Gráfico 4 - Evolução da Banda Larga x Tv por assinatura (milhões de usuários)

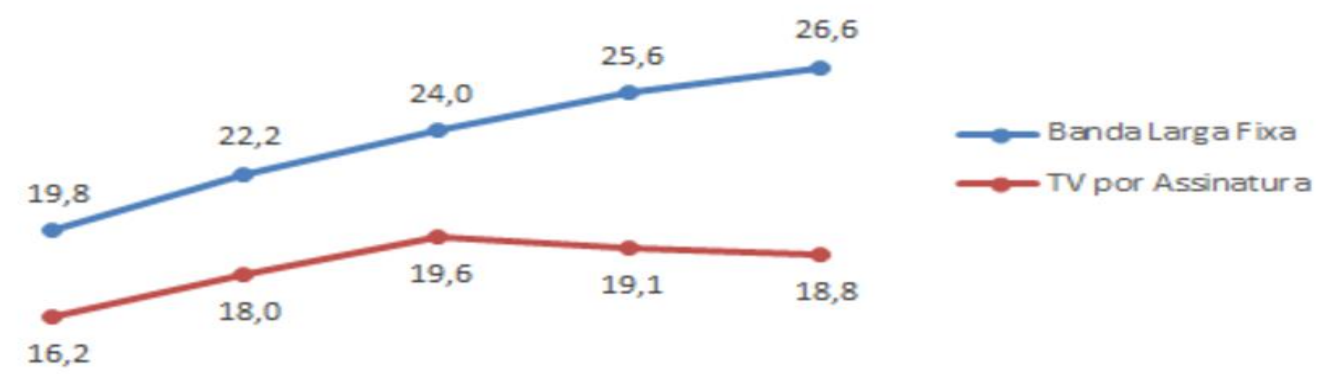

$2012 \quad 2013 \quad 2014 \quad 2015 \quad 2016$

Fonte: Anatel 2017. 
Para confirmar o quanto dito nos parágrafos peito, vide o gráfico 05 abaixo, que mostra a evoanteriores (i.e., no sentido de que as TVs por assi- lução da parcela da população brasileira que posnaturas estão perdendo consumidores para OTTs sui conta em algum serviço de OTT de vídeo em de vídeo), em movimento diametralmente oposto território nacional, se estimando que o serviço ao das TVs por Assinatura, o número de assinantes deve alcançar 12,7\% da população em 2021. das OTTs de vídeo só tem crescido. A esse res-

Gráfico 5 - Evolução dos serviços de OTTs no Brasil

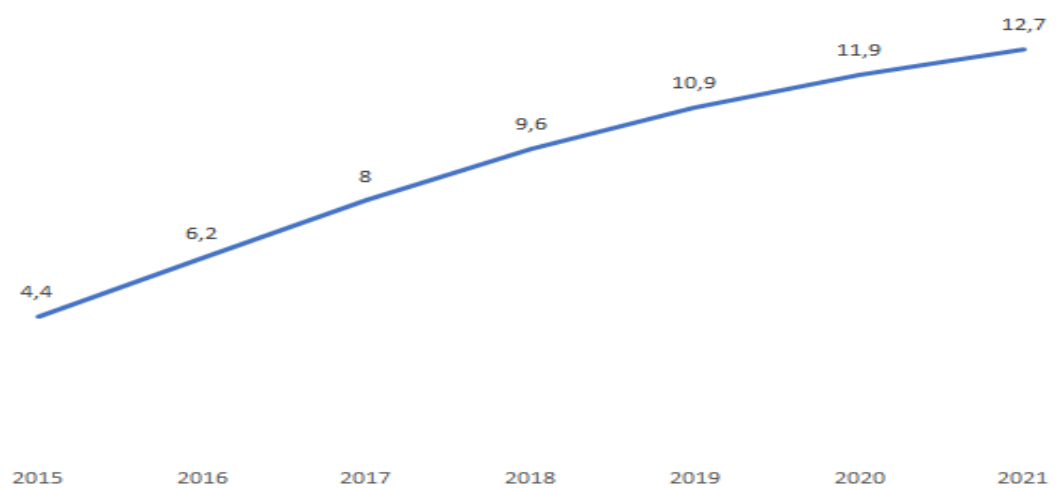

Fonte: Portal Stadista, agosto de 2016.

O Gráfico 6 mostra o market share das OTTs de vídeo no Brasil:

Gráfico 06 - Divisão de mercado das OTTs no Brasil (\% sobre o total de assinaturas), 2016

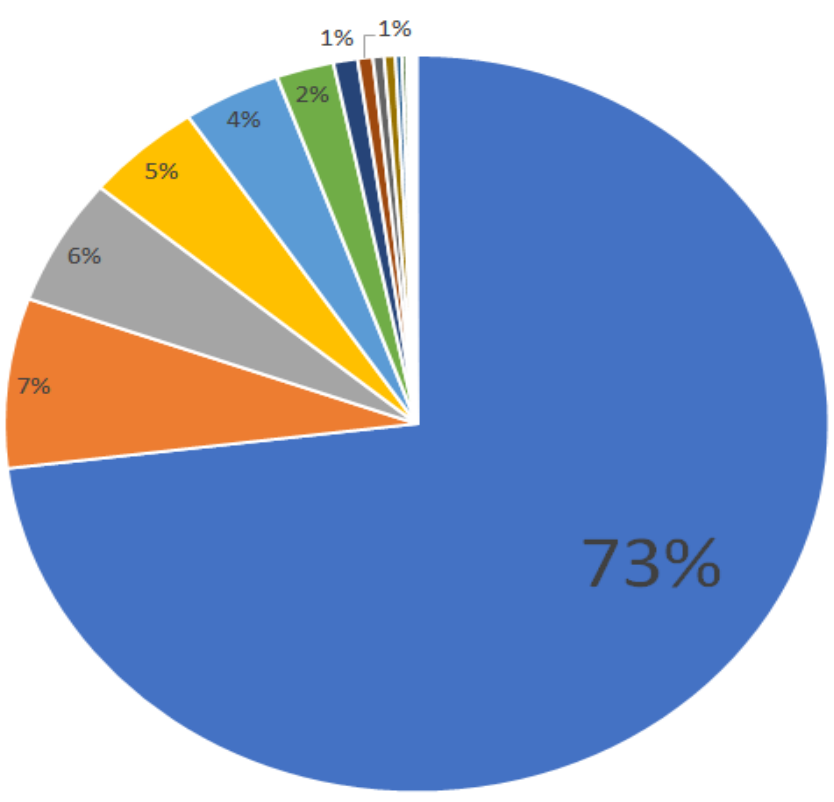

$$
\begin{aligned}
& \text { - Netflix } \\
& \text { - Esporte interativo } \\
& \text { - Sky Online } \\
& \text { m Ol Go } \\
& \text { - Clarovídeo } \\
& \text { - Globoplay } \\
& \text { - Looke } \\
& \text { - Vivo Play } \\
& \text { - Crunchyroll } \\
& \text { - Playkids } \\
& \text { - Netmovies } \\
& \text { - R7 Play } \\
& \text { - Drama Fever } \\
& \text { n Amazon Prime } \\
& \text { - Viki } \\
& \text { - Clap Me } \\
& \text { Mubi } \\
& \text { Fox Play } \\
& \text { - Oldflix } \\
& \text { - HBOGo } \\
& \text { - Selecta TV }
\end{aligned}
$$

Fonte: Dataxis 2016. 
Embora existam diversas OTTs de vídeo ten- considerados como mais populares não são aquetando se consolidar no mercado atualmente, a Net- les prestados por empresas tradicionais de TV por flix representa uma parcela substancial desse seg- Assinatura, mas sim por OTTs. Para mapear a tenmento. Superando com grande margem as empre- dência do mercado, a empresa de mídia Defy desas que oferecem serviços semelhantes, várias das senvolveu uma pesquisa com jovens americanos quais vinculadas a empresas de TV por Assinatura. entre 13 a 24 anos. Os entrevistados foram questiAliás, os principais serviços de mídia que hoje são onados sobre quais serviços de mídia "não viveriam sem":

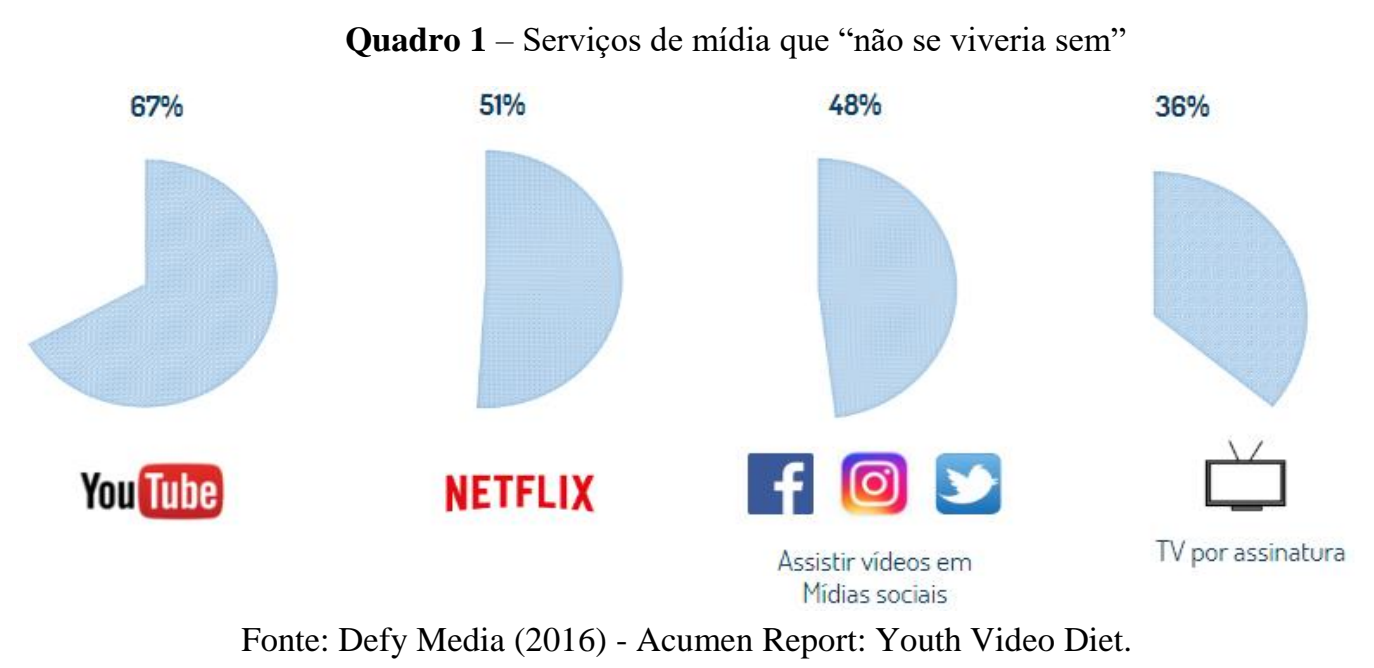

Entre os itens acima, a TV por assinatura aparece em último lugar com $36 \%$ dos jovens afirmando que "não viveriam sem". O dado denota uma tendência de que em um futuro próximo haverá migração massiva da audiência para as novas mídias.

da norma de proibição de propriedade cruzada. No entanto, pelos dados até aqui demonstrados, as OTTs hoje representam uma forte pressão competitiva às distribuidoras de TV por assinatura, com verdadeiro potencial disruptivo do setor. Diante das restrições trazidas pela Lei 12.485/11 à propri-

Ultrapassadas todas as informações acima, parece claro que existe um descompasso entre as análises que motivaram a Lei 12.485/11 e o cenário competitivo atual após a entrada das OTTs no mercado de conteúdo. Como visto anteriormente, os legisladores manifestaram preocupação com o poder econômico das empresas de telecomunicações, sendo essa a principal razão para a previsão edade cruzada, que retiram uma estratégia de competição que poderia ser utilizada no mercado como forma de diferenciação, resta saber, em detalhe, o modelo de negócio das OTTs, identificando o papel da verticalização no posicionamento competitivo desse segmento de entretenimento. Já existe um debate, no Brasil $^{28}$ e no mundo ${ }^{29}$, sobre o perfil de regulação que será adotado com relação às

\footnotetext{
${ }^{28}$ As tendências da regulação do setor podem ser observadas no Relatório de Consulta Pública sobre a Notícia Regulatória sobre a Comunicação Audiovisual sob Demanda e Recomendações da ANCINE para uma regulação da Comunicação Audiovisual sob Demanda. Disponível em: <http://teletime.com.br/wp-content/uploads/2017/05/Relatorio_Ancine_VoD.pdf>. Acesso em: 08 dez. 2017.

29 "O amadurecimento do mercado de audiovisual na União Europeia levou a rodadas mais recentes de consultas públicas
}

e avaliações dos resultados da regulação implementada na região. As consultas e avaliações buscaram identificar em que grau as disposições da Diretiva ainda se mantinham pertinentes após os avanços do mercado e o desenvolvimento tecnológico ocorrido nos últimos anos. Contribuiu para essa reflexão a concepção do Mercado Digital Único (Digital Single Market) europeu - que supõe uma redução das barreiras regulatórias entre os países da região para maior integração comercial e tecnológica - e a dependência desse projeto em 
$\mathrm{OTTs}^{30}$. No Brasil, estão em pauta questões relacionadas a direitos autorais, privacidade, neutralidade de rede e publicidade, além de contornos das competências das agências reguladoras em relação às OTTs e uma agenda tributária. Essa é particularmente uma discussão que deve ser feita com redobrado cuidado, levando em consideração as capacidades institucionais dos reguladores e, mais do que isso, o objetivo de desenvolver essas plataformas, ao invés de criar entraves burocráticos, até mesmo porque, a exemplo do que se ora se discute, diversas regulações aplicáveis a modelos hoje incumbentes podem não ser aplicáveis aos negócios desenvolvidos por meio de plataformas.

2 ESTRATÉGIA VERTICALIZADA (PRODUÇÃO + CONTEÚDO) DAS OTTS: VANTAGENS

Com exceções, o formato atual da TV por assinatura faz com que seja transmitida uma quantidade escassa de conteúdo, restrita a uma grade de programação de 24 horas diárias. Tal programação é preenchida por meio de uma seleção, entre um universo de conteúdos existentes, de materiais que (teoricamente) interessam mais ao público. Além de estar atrelada a essa forma de selecionar conteúdo, é necessário arcar com custos relativos à distribuição: emissão/transmissão ou broadcasting. Economicamente, esse modelo é viabilizado pelo pagamento de assinaturas e pela venda de tempo publicitário, bem como de produtos adicionais a exemplo do "pay-per-view", onde, mediante pagamento, o consumidor pode assistir o que deseja dentre as opções disponíveis.

relação à coesão regulatória entre os diferentes Estados Membros no campo audiovisual." Disponível em: <http://teletime.com.br/wp-content/uploads/2017/05/Relatorio_Ancine_VoD.pdf>. Acesso em: $08 \mathrm{dez} .2017$.

${ }^{30} \mathrm{O}$ relatório "OTT Regulation - Hot Topics: Level Playing Field, Privacy, Taxation, Net Neutrality, Platform and Competition" aborda os debates emergentes sobre a regulamentação dos serviços OTT em diversos países do mundo como França, Reino Unido, Alemanha, Holanda, Itália, Espanha,
Por outro lado, as plataformas OTTs de vídeo, permitem que o usuário organize sua programação de modo autônomo e com o auxílio de filtros, não existindo a limitação de uma grade de programação. A Netflix, por exemplo, que junto com o YouTube é responsável por 50\% do tráfego de dados de internet da América do Norte, desenvolveu um complexo algoritmo capaz de analisar os gêneros de filmes e séries disponíveis; o histórico de transmissão e as classificações que foram dadas pelo usuário e, por fim, cruzar essas informações com as classificações de todos os assinantes do serviço que possuem um gosto parecido. Essa solução de Big Data auxilia o mercado de streaming de vídeo a entender o comportamento dos assinantes e oferecer respostas rápidas às demandas.

\section{Por utilizar o modelo de Big Data como} forma de mapear os interesses dos consumidores, contribuindo para uma experiência que esteja mais em linha com o esperado pelo assinante, a plataforma de $O T T$ acaba gerando eficiência alocativa. A forma pela qual isso se torna possível depende de uma lógica de integração vertical envolvendo a produção de conteúdo conjunta com a sua distribuição. O fenômeno do binge watching (disponibilização de temporadas inteiras de séries) está em muito relacionado com a produção de conteúdo próprio, um diferencial que atrai um número cada vez maior de consumidores que, por sua vez, terão suas preferências e gostos devidamente mapeados, recebendo sugestões de conteúdos similares, além de fornecerem dados para a construção de um conteúdo mais adequado para os gostos dos assinantes, a partir do algoritmo criado. Não à toa a Netflix vem investindo constantemente em produções

EUA, Canadá, Brasil, Japão, Índia e Hong Kong. Os temas mais correntes são relacionados à tributação, privacidade e às regras de concorrência. No contexto de condições de igualdade, muitas vezes promovidas pelos operadores de telecomunicações, os regulamentos em torno da Neutralidade da Rede e das comunicações OTT também estão sob o destaque. Disponível em: <https://www.researchandmarkets.com/research/55h2kw/ott_regulation>. Acesso em: 08 dez. 2017. 
originais de filmes, documentário e séries como: ainda são limitadas. Para fins regulatórios, a $T V$ "Narcos", "Orange is the New Black" e "House of everywhere é considerada uma extensão do serviço Cards", que alcançaram sucesso mundial, já com de TV por assinatura, não possuindo as vantagens indicações de prêmios de crítica. Na projeção de introduzidas pelas OTTs, não contando com a es2017, a Netflix informou que estima gastar cerca tratégia de produção original potencializada pelo de US\$6 bilhões com produção original. ${ }^{31}$

uso de Big Data e individualização de experiência.

A verticalização ainda permite um modelo Tanto é assim que vários produtores de conteúdo de controle de custos não disponível para distribui- estão lançando plataformas próprias, o que se pode doras de TV por assinatura. Conforme recente entrevista do CEO da Netflix, explicando o cancelamento de Sense8 e Get Down ${ }^{32}$, duas séries populares da plataforma, mesmo algumas séries que têm sucesso podem não justificar a renovação, se o custo de oportunidade para produzir novas possibilidades de hits não se comprovar eficiente. A série 13 reasons why é um exemplo de um sucesso inesperado, que só ocorreu por conta da estratégia de diversificação do número de séries produzidas, um dos aspectos positivos que o modelo de verticalização viabiliza (i.e., ao invés de concentrar em séries de sucesso, a companhia pode optar por controlar os custos e diversificar constantemente, viabilizando a entrada de conteúdo novo a todo instante, com um maior número de apostas).

Embora a TV por assinatura esteja investindo na adoção do modelo TV everywhere, que pode ser oferecida a assinantes de TV por assinatura ou gratuitamente para usuários da TV aberta, as opções disponibilizadas para os espectadores ver de movimentos da $\mathrm{HBO}^{33}, \mathrm{FOX}^{34} \mathrm{e}$, em breve, da Disney ${ }^{35}$, todos eles com estratégias de mercado que focam em comercialização direta para o consumidor.

Ainda que a transmissão linear recebida tradicionalmente por aparelhos de TV e os serviços de demanda oferecidos por meio de internet, como é o caso de Netflix, apresentem pontos de divergência quanto às facilidades e tipos de opções oferecidas, em grande parte eles disputam o mesmo nicho de mercado que a TV por assinatura, o que tende a crescer a partir dos novos consumidores que cada vez mais deixam de ser imigrantes digitais e, portanto, se tornam mais afeitos à tecnologia. É perfeitamente viável ao consumidor, após a entrada da Netflix no mercado, optar por arcar com uma assinatura em complemento à TV aberta, para ter acesso à programação ao vivo e a filmes, séries e documentários, com a vantagem de poder moldar a programação e horários de acordo com a sua preferência, comportamento esse, aliás, que pode ser

\footnotetext{
${ }^{31}$ Como destaca Macdonald (2014), trata-se de um serviço inovador que fornece essencialmente um pacote de TV a cabo via banda larga. Cf. MACDONALD, Maggie. Comcast V. Netflix: Why the FCC should redefine multi-channel video programming distributors to include Over-the-Top Video providers. Colorado Technology Law Journal, v. 12, p. 479-498, 2014.

32 "A estratégia é simples: lança uma série, vê se ela faz sucesso. Fez muito sucesso, renova para uma próxima temporada. Não fez muito sucesso, cancela. 'Temos um índice de acerto muito alto agora. Cancelamos pouquíssimas series. Eu estou sempre pressionando o grupo de conteúdo, de que temos que tomar mais risco, tentar mais coisas loucas. Deveríamos ter um índice de cancelamento mais alto'.” Disponível em: <https://conteudo.startse.com.br/siliconvalley/felipe/netflix-cancela-duas-series-populares-e-ceo-diz-quequer-cancelar-ainda-mais/>. Acesso em: 24 set. 2017.
}

${ }^{33} \mathrm{O}$ serviço de streaming $\mathrm{HBO}$ GO permite aos assinantes terem flexibilidade e acesso imediato ao conteúdo do catálogo dos canais HBO. Disponível em: <https://www.hbogo.com.br/landing >. Acesso em: 24 set. 2017.

34 “O Fox Premium App \& TV dá acesso aos canais Fox Premium 1 e Fox Premium 2 via streaming, além de possibilitar o usuário a assistir as séries do canal, como The Young Pope, Feud, Taboo e Black Sails." Disponível em: <http://www.meioemensagem.com.br/home/ultimas-noticias/2017/08/14/fox-anuncia-streaming-para-nao-assinantes.html>. Acesso em: 24 set. 2017.

${ }^{35}$ A Disney encerrou o acordo com a Netflix para criar um serviço próprio de streaming, que estará disponível a partir de 2019. Disponível em: <http://www1.folha.uol.com.br/ilustrada/2017/08/1908195-disney-abandona-netflix-para-criar-servico-proprio-de-streaming.shtml>. Acesso em: 24 set. 2017. 
um dos fatores que explica a perda de assinantes da TV por Assinatura.

Além disso, em um futuro próximo, é possível que as OTTs ofereçam opções muito atrativas de plataformas de esportes. Essa é uma tendência que vem se consolidando, a exemplo de movimento recente da UEFA que decidiu vender os direitos de mídia da Champions League. A decisão foi tomada com o objetivo de eliminar distorções entre organismos de radiodifusão e concentração da mídia e permitir o desenvolvimento de serviços esportivos via Internet, uma tendência com grande potencial (devido à popularização dos smartpho$n e s)$ e de grande interesse dos fãs e consumidores em geral $^{36}$.

O debate sobre a verticalização nos serviços de telecomunicações vem se adensando em diversos países do mundo, sobretudo nos Estados Unidos e Europa, como alternativa para o novo cenário tecnológico. A Comissão Europeia, EUA, Canadá, China e Filipinas, por exemplo, já aprovaram operações que resultaram em integração vertical (unindo diferentes elos da cadeia de fornecimento da TV por assinatura). Na prática, isso significa que o Brasil tem umas das políticas mais restritas com relação à verticalização, agora que OTTs podem se verticalizar e TVs por assinatura, não.

A Netflix soube combinar o licenciamento de conteúdo de terceiros com a produção própria. A mesma tendência é seguida por programadoras que procuram meios para a desintermediação, criando serviços próprios de OTT. Endossando essa tendência, as empresas de TV por assinatura mais desenvolvidas do mundo, Comcast e BSKyB, também se tornaram verticalmente integradas. Megan Sieffert (2012) $)^{37}$, ao debater os benefícios e malefícios da integração vertical, destaca o potencial de

\footnotetext{
${ }^{36}$ Mais informações em: Commission welcomes UEFA's new policy for selling the media rights to the Champions League. Disponível em: <http://europa.eu/rapid/press-release_IP-02-806_en.htm?locale=en $>$. Acesso em: 06 set. 2017.

${ }^{37}$ SIEFFERT, Megan. Conception to Distribution: Vertical Integration in the Television Production and ISP Industry.
}

redução de preços. Tal fato pode ocorrer devido à consolidação dos custos. Pode haver também incentivo ao investimento em produtos mais arriscados, trazendo grandes benefícios ao consumidor. A redução de custos ocorre onde há processo de "dupla marginalização", quando o consumidor acaba arcando com o lucro de mais de uma empresa (produtora e distribuidora). E uma eficiência do processo de verticalização certamente está associada à redução de custos de transação. Com a produção de conteúdo próprio, as empresas podem focar em reduções de preço e na diversificação do conteúdo que é disponibilizado para os consumidores de sua plataforma.

A redução dos custos de transação se dá por vários motivos, mas é particularmente substancial porque o fim da restrição à propriedade cruzada eliminaria, para o conteúdo próprio (até porque as OTTs também são adquirentes de conteúdo de terceiros), inúmeras etapas de negociação entre distribuidoras e produtoras, permitindo a transmissão de conteúdo para qualquer meio, incluindo-se aí os dispositivos de transmissão (celular, televisão etc) e as tecnologias de transmissão (internet, satélite, radiofusão).

Por isso, a literatura identifica que a avaliação dos efeitos concorrenciais de uma verticalização seja feita caso a caso, já que existem fortes eficiências associadas ao modelo de negócio, aqui potencializadas pelo uso de tecnologia e de dados para alterar a experiência do consumidor de serviços de conteúdo. Nesse sentido, vale acompanhar as reflexões de Christopher S. Yoo (2002) ${ }^{38}$, que afirma que, para que uma determinada instância de integração vertical prejudique a concorrência, provavelmente é necessário que ocorra um conjunto bastante refinado de predicados factuais. Para o

The Journal of Business, Entrepreneurship \& the Law, Malibu, v. 06, n. 01, 2012.

${ }^{38}$ YOO, Christopher S. Vertical Integration and Media Regulation in the New Economy. Yale Journal on Regulation, $\mathrm{v}$. 19 , p. 171-300, 2002. 
autor, na medida em que os perigos anticoncorrenciais apareçam, devem ser abordados em um fórum, como um tribunal antitruste, que pode avaliar cada situação com base em seus fatos individuais.

3 REAÇÃO DOS AGENTES REGULATÓRIOS Às VANTAGENS DAS OTTS: ASSIMETRIA REGULATÓRIA

Em dezembro de 2016 a Ancine chegou a fazer uma consulta pública sobre a regulamentação da oferta de conteúdos audiovisuais sob demanda aos consumidores brasileiros, tendo em mente os seguintes pilares: "a busca da ampliação da diversidade na oferta de conteúdos audiovisuais; a segurança jurídica; a isonomia entre os agentes econômicos que atuam nos segmentos do mercado audiovisual e a perspectiva de desenvolvimento dos serviços e da economia audiovisual do país".

Um dos pontos de conclusão da Agência Reguladora a partir desse procedimento de consulta pública foi que, para garantir recursos para o financiamento à produção audiovisual brasileira independente e para adequar a forma de incidência da CONDECINE às características específicas desse mercado, será preciso adotar as seguintes medidas:

a) Ter como fato gerador a aquisição de receita decorrente da comunicação audiovisual sob demanda, por meio da oferta de catálogo para fruição por usuário através de serviço de vídeo sob demanda ou plataforma de compartilhamento de conteúdo audiovisual; b) Ter como sujeitos passivos os provedores do serviço de vídeo sob demanda e os responsáveis pelas plataformas de compartilhamento de conteúdos c) Ter como base de cálculo a receita bruta anual dos contribuintes, apurada nos termos da legislação do imposto de renda, relativa às receitas decorrentes da cessão de espaço publicitário e inserção publicitária; assinatura, direta ou indireta, para acesso a catálogo, no todo ou em parte; e aluguel, cessão ou venda de conteúdo audiovisual individualizado; d) Ter alíquotas estabelecidas progressivamente, iniciando em $0 \%$ para a parcela de receita bruta anual até $\mathrm{R} \$ 3,6$ milhões e tendo como limite $4 \%$ para a parcela de receita bruta anual acima de $\mathrm{R} \$ 70$ milhões ${ }^{39}$.

Existem, portanto, indicativos de que as OTTs deverão ser submetidas a uma discussão mais pesada por parte dos órgãos reguladores sobre potencial taxação. No entanto, o ponto que os reguladores deveriam enfrentar não é buscar paridade entre o modelo regulatório das empresas de TV por assinatura e as $O T T \mathrm{~s}$, mas sim uma revisão mais profunda do marco regulatório. É preciso averiguar o cenário competitivo atual: a verticalização é utilizada como uma estratégia pelas OTTs, oferecendo maior eficiência alocativa ao setor; no entanto, essa opção não é viável às empresas de TV por assinatura.

Bastaria, portanto, endereçar as preocupações competitivas que decorrem da verticalização entre produção e distribuição por meio de normas alternativas, menos restritivas à possibilidade de verticalização, mais focadas em prevenir os riscos concorrenciais, mas permitindo que as empresas de TV por Assinatura sejam autorizadas a produzir e distribuir conteúdo, de modo a possibilitar que elas acompanhem a inovação tecnológica. Como medidas focadas a endereçar os riscos competitivos decorrentes da verticalização, seriam possibilidades, entre outros exemplos, exigir medidas de não discriminação, acompanhadas de obrigações de transparência, a fim de viabilizar o monitoramento constante das regras regulatórias vigentes pelo órgão responsável. Lembre-se que ambos os modelos, TV por Assinatura e OTTs, estão sujeitos à norma brasileira de defesa da concorrência, Lei 12529/2011, respondendo por qualquer eventual

39 Disponível em: <https://www.ancine.gov.br/sites/default/files/Vod\%20Documento\%20P\%C3\%BAblico\%20Final\%20v3_2.pdf>. Acesso em: 06 set. 2017. 
violação e demandando análise prévia para qual- por tendências em mercados utilizados como quer operação que se enquadre nos patamares le- benchmark.

gais.

É importante lembrar que, apesar de produzirem conteúdo próprio, as OTTs de vídeo também são consumidores de conteúdo de produtoras, o que, por sua vez, também tem um impacto positivo no arrefecimento de parte dos riscos competitivos que estão associados à verticalização (como aqueles que derivam de estratégias de fechamento de mercado). Todo um mercado em crescimento remanesceria disponível para competidores.

\section{CONCLUSÃO}

Basicamente, diante das novas estratégias de mercado que se tornaram possível em função da inovação tecnológica e da evolução da infraestrutura de banda larga, é possível concluir que existe atualmente uma defasagem regulatória que merece reparo. Tal defasagem é inerente ao período em que a Lei $12.485 / 11$ foi elaborada. $\mathrm{Na}$ ocasião não era possível prever o efeito disruptivo sobre o mercado que seria ocasionado pelas OTTs de vídeo. Existe hoje um cenário crescente de assimetria regulatória resultante da rigidez imposta apenas às empresas de TV por assinatura. Tal cenário precisa ser contornado.

A inclusão das OTTs no mercado pode ser compreendida como um avanço tecnológico de natureza irreversível que caminha junto à difusão da internet, com forte potencial disruptivo para estratégias tradicionais de produção e distribuição. Esse serviço traz resultados positivos, como a ampliação da possibilidade de escolha para o consumidor, que passa a ter a seu dispor um serviço de streaming de vídeo que exerce forte pressão competitiva no mercado de TV por para equiparar o mercado, mas sim a abertura de assinatura, reduzindo seu potencial de novas possibilidades para que as empresas de TV crescimento, algo já demonstrado pelos dados e por assinatura possam se reinventar.

A revogação da norma que prevê a restrição da propriedade cruzada traria mais equidade às empresas de TV por assinatura frente ao desenvolvimento tecnológico que se consolida e poderia, ao invés do imaginado à época da discussão do seu respectivo projeto de lei, contribuir para mais competição. Tais empresas poderiam concentrar mais investimentos em conteúdo próprio criando diferenciais para atrair os consumidores e diversificar a oferta de serviços, gerando ofertas de serviços mais heterogêneas, ampliando a escolha do consumidor. $\mathrm{O}$ modelo mais verticalizado reduziria também os custos de transação, eliminando etapas de negociação, ampliando as condições de competição com as empresas de streaming service, que oferecem preços cerca de 50\% inferiores aos oferecidos pela TV por assinatura, viabilizando maiores escalas de prestação.

É preciso modelar um ambiente regulatório que permita as melhores condições para o avanço da tecnologia. E revisar marcos regulatórios quando as condições de mercado se alteram, até mesmo para viabilizar novos modelos de negócio e novos posicionamentos estratégicos. É relativamente normal e esperado que, em mercados que sofrem influência de inovação, a alteração de regras regulatórias seja algo comum, o que parece ser o caso da restrição à propriedade cruzada. Trata-se de uma barreira a ser rompida que obriga um setor a parar no tempo e se tornar obsoleto em comparação a uma plataforma altamente dinâmica e constantemente premiada por seus méritos na produção de conteúdo. O ideal, portanto, não seria a imposição de novas restrições 


\section{REFERÊNCIAS}

D'ARMA, Alessandro. Content aggregation in the age of online video: an analysis of the impact of internet distribution on the television business. Journal of Media Business Studies, v. 08, n. 03, p. 117, set. 2011.

GIVEN, J., CURTIS, R.; MCCUTCHEON, M. Online video in Australia. International Journal of Digital Television, v. 03, n. 02, p. 141-162, 2012.

MACDONALD, Maggie. Comcast V. Netflix: Why the FCC should redefine multi-channel video programming distributors to include Over-the-Top Video providers. Colorado Technology Law Journal, v. 12, p. 479-498, 2014.

OECD. OECD Communications Outlook 2013. Paris: OECD Publishing, 2013. Disponível em: <http://dx.doi.org/10.1787/comms_outlook-2013-en>. Acesso em: 31 dez. 2017.

POSSENON, Samuel. TV por assinatura: 20 anos de evolução. São Paulo: Save Produções, 2009.

SIEFFERT, Megan. Conception to Distribution: Vertical Integration in the Television Production and ISP Industry. The Journal of Business, Entrepreneurship \& the Law, Malibu, v. 06, n. 01, 2012.

WATERMAN, David. The Economics of Internet Television: New Niches vs Mass Audiences. Info: the Journal of Policy, Regulation and Strategy for Communications, Information and the Media, v. 03, n. 03, p. 215-228, 2001.

WEDGE, G.; Lancaster, B. Over-the-Top Services. Pipeline, v. 04, n. 07, 2007. Disponível em: <http://www.pipelinepub.com/1207/pdf/Article_3.pdf>. Acesso em: $31 \mathrm{dez} .2017$.

YOO, Christopher S. Vertical Integration and Media Regulation in the New Economy. Yale Journal on Regulation, v. 19, p. 171-300, 2002.

Recebido em: 20/10/2017

Aceito em: 14/12/2017 
